\title{
MORPHO-HISTOLOGICAL STUDY OF SPLEEN ONTOGENESIS IN LAMBS DURING ANTENATAL AND POSNATAL PERIOD
}

\author{
Rahmoun EDDINE DJALLAL ${ }^{\star{ }^{1}}$, Fares AMINE MOHAMED ${ }^{1}$, Haffiene MANEL ${ }^{1}$, Messai KHAOULA ${ }^{1}$ and \\ Lieshchova MARINA² \\ ${ }^{1}$ Laboratory of Histology, Departement of Veterinary Science, Institut of Agronomic and Veterinary Science Taoura, University of Souk Ahras, Algeria \\ 2Faculty of Veterinary Medicine Dniepro, Ukraine \\ Email: deddine44@hotmail.com; (1) ORCiD: 0000-0001-6723-4491 \\ Supporting Information
}

\begin{abstract}
In an experiment on the spleen of healthy lambs at two periods (prenatal and postnatal), using anatomo-topographic and histo-cytological research methods and with subsequent statistical analysis, it was found that the changes in the anatomical and histological structure related to the age of this organ, including during the early stages of the postnatal period of ontogenesis. Note that the surface of the spleen is covered with a capsule of connective tissue, from which leave trabeculae which divide the parenchyma of the organ into lobes. At the time of physiological maturity, the ratio of the structures changes in the direction of an increase in the white pulp and a decrease in the component of the red pulp. During all periods of prenatal fetal development, the percentages of spleen tissue components corresponding to fetal analogs with normal clinical development are determined. The morphological structure of the spleen is described for the first time for this breed in Algeria, age-related changes in the structures of the parenchyma are traced, the formation of follicles began during the terminal phase of gestation, and the development age-related white pulp.
\end{abstract}

Keywords: Algeria, Follicle, Parenchyma, Postnatal, Spleen, Lambs, White pulp.

\section{INTRODUCTION}

The spleen is a secondary lymphoid organ with dual function; Immune and hematopoietic at the same time (Short et al., 2016). Spleen studies in sheep have been done by Gnanadevi et al. (2019), in addition, extensive studies on the human spleen have been performed by Almenar et al. (2019). Also the white pulp of spleen is mainly populated by lymphocytes. The areas of white pulp include arterial vessels, surrounded by lymphoid tissue, with clear boundaries. In addition, in white pulp of rabbit's spleen there are lymphoid follicles grouped by lymphoid cells. According to Rahman et al. (2016), they are surrounded by a well-defined connective tissue. These lymphoid follicles belong to B-dependent lymphoid tissue that the researchers found by Mollejo et al. (2002).

With regard to other animals, the white and red pulps are distinguished in the spleen of rabbits previously studied by Rahmoun et al. (2019), also white pulp of spleen is mainly populated by lymphocytes. The areas of white pulp include arterial vessels, surrounded by lymphoid tissue, with clear boundaries (Quesada et al., 1990). In addition, in white pulp in rabbit's spleen there were lymphoid follicles grouped by lymphoid cells, surrounded by well-defined connective tissue. These lymphoid follicles belong to the B-dependent lymphoid tissue that found by the researchers (Rebelatto et al., 2018). Papenfuss et al. (2017) described that at the level of the white pulp, the lymphoid sleeve is presented by a mass of $\mathrm{T}$ lymphocytes around the central arteries lymphoid follicles, also attached to the sleeves formed by B lymphocytes are composed of a clear germ center corresponding to the transformation zone of the lymphocytes into plasma cells and a darker crown where lymphocytes proliferate.

Our research based on the study of growth and development of this organ in antenatal and postnatal period according to the norms of descriptive immunology of lymphoid organs theories and highlighting the activation of follicles after the contact with antigen.

\section{MATERIALS AND METHODS}

Spleens from fetuses, as well as lambs healthy and unvaccinated from the slaughterhouse city of souk ahras, Algeria, were the subject of our study, the collected spleens were performed immediately after slaughter dissection of animals for the antenatal period, and from the pregnant female during the last month of gestation. After collecting organs, the spleens are weighed with an electronic High precision balance KERN KB $0.001 \mathrm{~g}$ and the length and width are taken with electronic Ruler Measuring Stainless Steel LCD, the data is entered in the note-book. 
Organ fixation was performed with $5.0 \%$ and $\mathbf{1 0 . 0 \%}$ formalin. The research was performed in the histology and histopathology laboratory of Taoura Veterinary Institute, University of Souk Ahras, Algeria. Organ fixation was performed with $\mathbf{5 . 0 \%}$ and $\mathbf{1 0 . 0 \%}$ formalin. The organs have been sectioned and placed in a coating cassette, placed in the initial pot of automat impregnation SLEE MEDICAL, which includes 12 stations, ten glass beakers for xylene and alcohol with digressive degrees of treatment and two pots of paraffin in anodized aluminum. For dehydration and preparation of tissue for microtome cutting Programmable thanks to the LCD screen, for control of temperature and elapsed time. The step of coating the tissue samples with the MPS / P1 system. Thin sections of 5.007 .00 microns were made with a CUT 4062 microtome with manual rotation, put on slide for different staining, Hematoxylin-eosin, impregnation with silver nitrate, and immuno-histochemistry with markers identification of T lymphocytes.

Examination with an ocular micrometer, distances between divisions of $5 \mu \mathrm{m}$. The histological structure of the parenchyma has been detected. The measurements of each ocular field were carried out in five fields of vision of five histological sections of each histological slide.

Other sections were subjected to an impregnation with silver nitrate by serial passage in silver nitrate and potassium permanganate tanks at a decreasing concentration and this in order to visualize the reticular structure of this organ. For localization of lymphocytes in the functional areas of the spleen, immunohistochemistry is used for the determination and localization of lymphocytes and macrophages in the parenchyma of organs, also the determination of the cytological characteristics was carried out using an ocular microscope, antibodies were used to elucidate the T lymphocytes in the functional areas of the spleen.

The examinations and the taking of the data were carried out on personal computer. The determination of the histological and cytological characteristics was carried out using an ocular microscope and a stereo MBS-10 microscope. The quantitative study for the tissue compartments was carried out using the point $\mathrm{S}$ system; the data obtained were analyzed with $\mathrm{R}$ program.

\section{RESULTS AND DISCUSSION}

The study of the mass of spleens during the antenatal period revealed that the minimum value was $2.43 \mathrm{~g}$ found in the first group, while the maximum value was $6.39 \mathrm{~g}$ found in the fourth group (Graph 1), concerning lambs. From the postnatal period, the minimum value was $6.22 \mathrm{~g}$ found in the first group, while the maximum value was $21.52 \mathrm{~g}$ found in the fourth group (Graph 1). The results of morphometric study and mass of this organ on other mammals were conducted by Vashishtha et al. (2018). Finding significant variations according to age, also, discussed a progressive increase of mass and revealed that sex has no influence on its development, results found by Jaji et al. (2019). Measurement of fetal spleens, minimum value of length was $3.61 \mathrm{~cm}$ found in first group while maximum value was $4.35 \mathrm{~cm}$ found in fourth group. About width, minimum value was $2.47 \mathrm{~cm}$ found in second group, whereas maximum value was $2.95 \mathrm{~cm}$ for the fourth group (Graph 2). Regarding lambs spleen, the minimum length value of $4.54 \mathrm{~cm}$ found in first group and maximum value of $11.67 \mathrm{~cm}$ found in fourth group. While minimum width value was $3.29 \mathrm{~cm}$ found in first group, and maximum width was $8.32 \mathrm{~cm}$ found in fourth group (Graph 2).

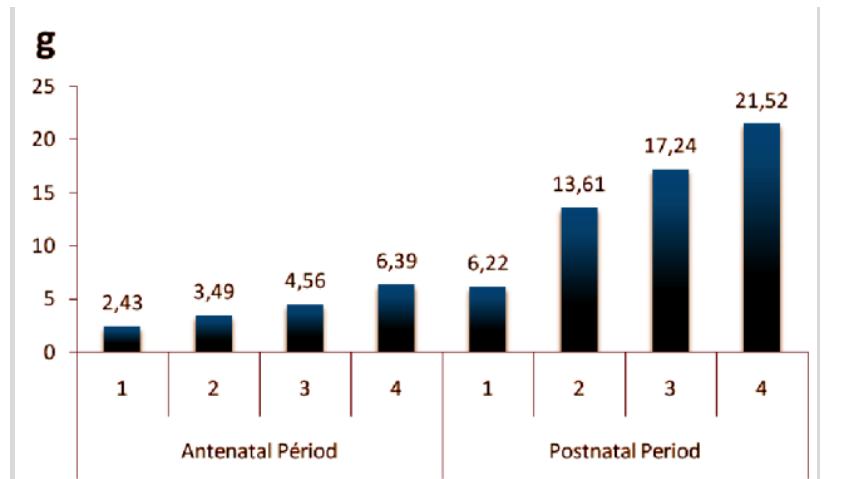

Graph 1 - Mass index of spleens (g) according to antenatal and postnatal period (days).

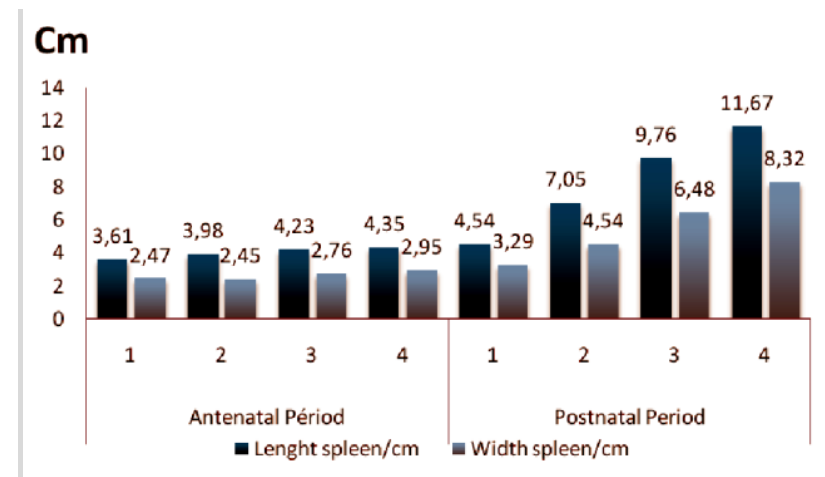

Graph 2 - Morphometric index of some spleens, (cm) according to the age (days).

Optical Microscopic exams revealed that lambs' spleen consisted of stroma and parenchyma (Graph 3). Stroma mainly formed by capsule and trabeculae that enter into parenchyma. The capsule of this organ consists of two layers, an external connective tissue (elastic) and internal (muscle), according to Weigert's Hematoxylin and picrofushin (Van Gieson) staining allowing the organ to change its size and maintain an increase significant of its volume (Figure 1-A). It has been found that red pulp is composed of splenic sinusoidal capillaries and cellular cords. Splenic sinusoidal capillaries are limited by single discontinuous epithelium, resting on basement membrane which surrounds sinusoids in discontinuous way, species situated between sinusoidal capillaries occupied by cellular cords, in the researches of Silva-O'Hare et al. (2017) have achieved almost the same results, although follicles appeared in the antenatal phase according to our data, which is not in theory as immunological norm, this result would open new research later. 
The results obtained after silver nitrate staining revealed white pulp is composed of lymphatic follicles, integrated in different places of red pulp in the form of small rounded growths. Arteries that cross the periphery were observed. Vascularization of red pulp takes its origin from penicillate arteries that give rise to arterioles (Figure 2-F), whereas endothelial cells and smooth muscle cells are clearly visible in the center (Figure 2-E). Gavrilin et al. (2017) noted that fibers were arranged vertically in trabeculae and gradually became shallow in terminal branches. Elastic and muscular fibers oriented in a parallel way to trabeculae direction, their function is changing volume, whereas smooth muscle function is discharging blood from the organ. White pulp rich in reticular tissue found to have silver nitrate impregnation of histological sections also was observed (Ikpegbu et al., 2019).

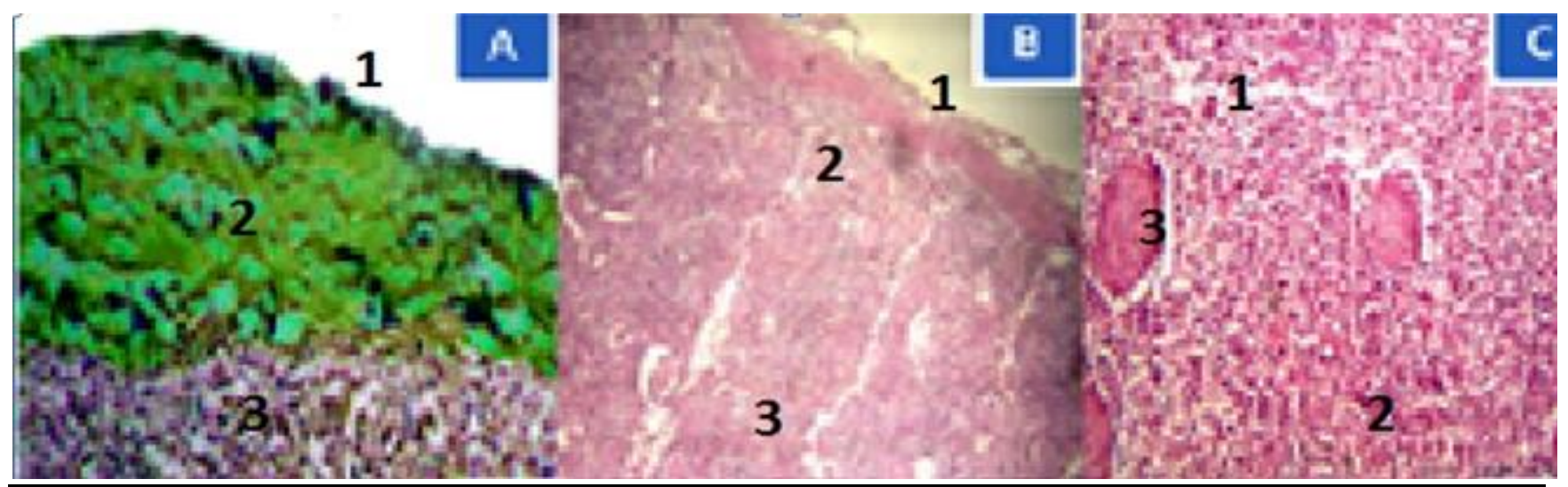

Figure 1: (a) Histological section of newborn lamb spleen, Hematoxylin \& eosin, x 40: 1-capsule; 2-muscle fiber; 3Cortical zone. (b) Histological section of lamb fetus spleen, Hematoxylin \& eosin, $\times$ 40: 1-capsule; 2-cortical area; 3Medullar area; 4- Trabeculae artery. (c) Hematoxylin \& eosin, $\times$ 40: 1- Pulp artery; 2 - Trabeculae artery; 3-red pulp.

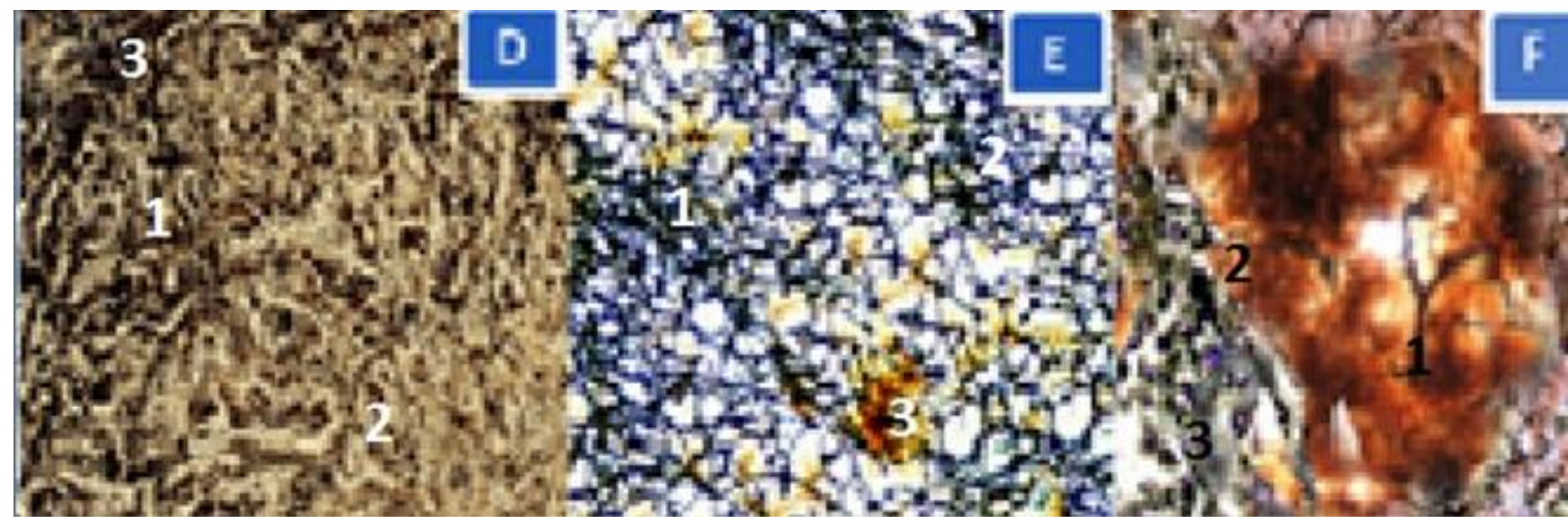
Figure 2: (D) Histological section of lamb fetus spleen, silver nitrate impregnation, $\times$ 40: 1-sinus; 2-early formation of reticular tissue; 3-medullary area. (E) Histological section of the lamb spleen, silver nitrate impregnation, $\times 40: 1$ zone of reticular fiber formation; 2-pulp artery. 3-cortical area. (F) Histological section of the newly born lamb spleen: 1-pulp artery, 2-PALS, 3-lymphocyte cell accumulation.

Hassal corpuscles and a peri-arterial lymphatic sheath also were noted (Figure 1-F). Results are similar to those reported by Shringi et al. (2018). Splenic follicles were well visualized, of different sizes, as an ovoid mass, composed of aggregates of lymphatic tissue and small pulpal arteries (Figure 1-C), as described by Dubey et al. (2018), space between white pulp and trabeculae occupied by red pulp, similar results were observed in other studies. It has also been noted that red pulp is composed of pulpal arterioles, splenic follicles, and splenic cords (Nicander et al., 1993). Quantitative results in antenatal period revealed after microscopic examination that spleen is composed of capsule which envelops the whole organ (Figure 1-B), its index increases according to groups, $02.34 \pm 0.74 \%$ for first group, $03.48 \pm 0.83 \%$ for second group, third group of fetal spleen present value of $04.84 \pm 0.67 \%$ finally a sum of $06,66 \pm 0,24 \%$ assigned for the fourth group. For trabeculae, minimum percentages value of $02.71 \pm 0.87 \%$ found in second group, while maximum value is $09.35 \pm 0.24 \%$ for fourth group.

Red pulp and arteriolar peripheral lymphoid sheaths (PALS) begin to form only in fourth group antenatal spleens, while they are absent entirely in other groups of. Follicles in these groups have variable values, minimal value of $0.12 \%$ found if the first group, and maximal value of $1.74 \%$ in the fourth group. Whereas total parenchyma has a variable percentage occupies discrete invisible neo-formations, the Maximum value is $94.46 \pm 0.72 \%$ for the first group of fetal spleens, while it is at least $89.40 \pm 3.45 \%$ in fourth group. For lamb's spleens, it was noted that all parenchyma components are present, a noticeable increase in percentages of components tissue, capsule exhibited minimal value in second group $06.10 \pm 0.17 \%$, while maximum value was in fourth group $11.65 \pm 0.82 \%$. For trabeculae, the minimum 
value of $04.53 \pm 0.35 \%$ found in the first group and reaches $07.10 \pm 0.17 \%$ in the second group. For the red pulp, the minimal surface of $52.33 \pm 1.65 \%$ found in the first group, and a maximum of $72.54 \pm 1.62 \%$ in the fourth group. These results are similar to those found by (Dunaevskaya, 2019).

Peri-arteriolar lymphoid sheaths (PALS), revealed minimum surface of $07.70 \pm 0.78 \%$ lambs first group and maximal value of $13.34 \pm 0.76 \%$ in fourth group. Regarding follicles, inactive follicles percentage shows minimum value of $1.74 \pm 1.26 \%$ in first group and maximum value of $5.79 \pm 1.35 \%$ in fourth group. For active follicles, minimum percentage of $2.66 \pm 1.21 \%$ found in first group; whereas maximum value was in second group $8.29 \pm 2.54 \%$. Looking at total parenchyma percentage a maximum value of $88.75 \pm 1.87 \%$ in first group, and $82.7 \pm 1.85 \%$ as lowest value found in fourth group.
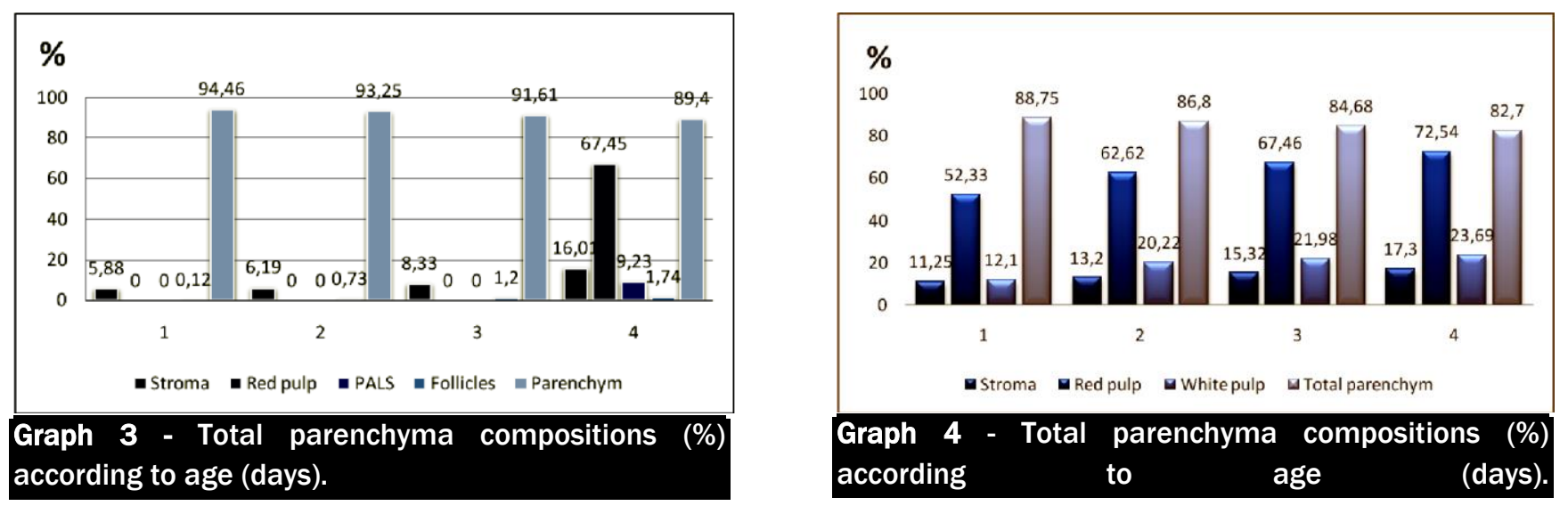

\section{CONCLUSION}

Spleen in ovine species in Algeria appears as an important multifunctional organ of peripheral element of immune system and hematopoiesis process. Results of this study obtained at macroscopic and microscopic level indicate that development index begins already in antenatal period then in post-natal period, stroma, red pulp and white pulp have development index appears normal whereas follicles appear already in antenatal period about gestation's end. The objective is to establish basic anatomical characters of spleen in Algerian breed Ouled Djellal, in order to obtain safe animal production. For this morphometricall and histologic spleens research gave an idea about the development index.

\section{DECLARATIONS}

\section{Corresponding Author}

E-mail: deddine44@hotmail.com; ORCID: 0000-0001-6723-4491

\section{Acknowledgements}

The authors wish to thank the team of the histology laboratory of the faculty of veterinary sciences of Taoura, University of Souk-ahras Algeria, for their support and help throughout the research period.

\section{Authors' Contribution}

All authors contributed equally to this work.

\section{Conflict of interests}

The authors declare that they have no competing interests.

\section{REFERENCES}

Almenar S, Rios-Navarro C, Ortega M, Molina P, Ferrandez-lzquierdo A and Ruiz-Sauri A (2019). Anatomy, immunohistochemistry, and numerical distribution of human splenic microvessels. Annals of Anatomy-Anatomischer Anzeiger, 224, 161-171. DOI: https://dx.doi.org/10.1016/j.aanat.2019.05.004 I PMID: 31121286 I Google Scholar

Dubey A, Jethani SL and Singh D (2018). Gestational age estimation in human fetuses from histogenesis of the spleen. SRHU Medical Journal, 1(2): 76-79. http://journal.srhu.edu.in/index.php/SRHUMJ/article/view/33/20 I Google Scholar

Dunaevskaya OF (2019). Anatomic characteristics of spleen Bos taurus taurus L. Bulletin of Problems of Biology and Medicine, 1 (1): 148. DOI: https://dx.doi.org/10.29254/2077-4214-2019-1-1-148-265-268.

Gavrilin PN, Gavrilina EG, and Evert VV (2017). Histoarchitectonics of the parenchyma of lymph nodes of mammals with different structure of intranodal lymphatic channel. Ukrainian Journal of Ecology, 7(3): 96-107. DOI: https://dx.doi.org/10.15421/2017 54 I Google Scholar 
Gnanadevi R, Senthilkumar S, Kannan TA and Ramesh G. (2019). Comparative Histoarchitectural Study of Splenic Components in Sheep and Goat. International Journal of Current Microbiology and Applied Sciences, 8(5): 1387-1394. DOI: https://dx.doi.org/10.20546/ijcmas.2019.805.158 I Google Scholar

Ikpegbu E, Ibe CS, Nlebedum UC and Nnadozie O (2019). The Spleen Morphology of the African Giant Pouch Rat (Cricetomys Gambianus-Waterhouse1840) from Eastern Nigeria. Journal of Animal Husbandry and Dairy Science, 3(1): 20-25. https://www.sryahwapublications.com/journal-of-animal-husbandry-and-dairy-science/pdf/v3-i1/5.pdf I Google Scholar

Jaji AZ, Saidu AS, Mahre MB, Yawulda MP, Girgiri IA, Tomar P and Dau F (2019). Morphology, Morphometry and Histogenesis of the Prenatal Dromedary (Camelus dromedarius) Spleen. Macedonian Veterinary Review. DOI: https://dx.doi.org/10.2478/macvetrev-2019-0018 I Google Scholar

Mollejo M, Algara P, Mateo M S, Sanchez Beato M, Lloret E, Medina MT and Piris MA (2002). Splenic small B cell lymphoma with predominant red pulp involvement: a diffuse variant of splenic marginal zone lymphoma?. Histopathology, 40(1): 22-30. DOI: https://dx.doi.org/10.1046/i.1365-2559.2002.01314.x I Google Scholar

Nicander L, Brown EM, Dellmann HD, Landsverk T (2018). In Text Book of Veterinary Histology.4th Ed. Ed. By Dellmann, H.D. pp. 129 - 133. Lea and Febiger, Philadelphia. https://ikmewedca1982.files.wordpress.com/2018/05/dellmanns-textbook-ofveterinary-histology-with-cd-jo-ann-coers.pdf.

Papenfuss TL and Cesta MF (2017). "Spleen" Immunopathology in toxicology and drug development (pp. 37-57). Humana Press, Cham. https://link.springer.com/chapter/10.1007/978-3-319-47385-7_2 I Google Scholar

Quesada J, Viilena M.I and Agulleiro, B. (1990). Structure of the spleen of the sea bass (Dicentrarchus labrax): a light and electron microscopic study. Journal of morphology, 206(3): 273-281. https://doi.org/10.1002/jmor.1052060304 I Google Scholar

Rahman N, Tandon R, Ghaus F, Moinuddin A, Akram W, and Faruqi NA (2016). Comparative Anatomy of Spleen: Histomorphometric Study in Human, Goat, Buffalo, Rabbit and Rat. DOI: https://dx.doi.org/10.21276/aanat.2016.2.1.6 I Google Scholar

Rahmoun DE, Fares MA, Bouzebda-Afri F, Ben Driss Kh (2019). Anatomical and histological study of the rabbit spleen development in the postnatal period in Algeria. Online Journal of Animal And Feed Research, 9(2): 44-50. http://www.ojafr.ir/main/attachments/article/139/0JAFR\%209(2)\%2044-50,\%202019.pdf I Google Scholar

Rebelatto MC (2018). Spleen, lymph nodes, and thymus. In Boorman's Pathology of the Rat (pp. 469-491). Academic-Press. DOI: https://doi.org/10.1016/B978-0-12-391448-4.00024-1 I Google Scholar

Shringi N, Mathur R, Kumar V, Rohlan K and Ganguly S (2018). Histological studies on the spleen of large white Yorkshire Pig (Sus scrofa). Journal of Entomolog and Zoology Studies, 6(1): $1142-1144$. DOI: https://dx.doi.org/10.22271/j.ento.6.1.257.1 I Google Scholar

Silva-O'Hare J, de Oliveira I S, Klevorn T, Almeida VA, Oliveira GG, Atta AM and dos-Santos WL (2016). Disruption of splenic lymphoid tissue and plasmacytosis in canine visceral leishmaniasis: changes in homing and survival of plasma cells. PLoS One, 11(5): e0156733. DOI: https://dx.doi.org/10.1371/journal.pone.0156733 I Google Scholar

Vashishtha K, Gaur V and Kapoor K. (2018). Morphometric study of human fetal spleen: a study from north-india. International Journal of Anatomy and Research, 6(4.3): 5983-88. DOI: https://dx.doi.org/10.16965/ijar.2018.390 I Google Scholar 